\title{
Glucocorticoid-Like Activity of Escin: A New Mechanism for an Old Drug
}

This article was published in the following Dove Press journal:

Drug Design, Development and Therapy

\author{
Luca Gallelli $\mathbb{D}^{1,2}$ \\ Erika Cione $\mathbb{D}^{3}$ \\ Tian Wang ${ }^{4}$ \\ Leiming Zhang ${ }^{4}$
}

'Department of Health Science, School of Medicine, Operative Unit of Clinical Pharmacology, Mater Domini University Hospital, Catanzaro, Italy; ${ }^{2}$ Research Center FAS@UMG, University Magna Graecia of Catanzaro, Catanzaro, Italy; ${ }^{3}$ Department of Pharmacy, Health and Nutritional Sciences, Department of Excellence 2018-2022, University of Calabria, Rende, 87036, CS, Italy; ${ }^{4}$ Key Laboratory of Molecular Pharmacology and Drug Evaluation (Yantai University), Ministry of Education, School of Pharmacy, Yantai University, Yantai, People's Republic of China
Correspondence: Luca Gallelli

Department of Health Science, School of

Medicine, Operative Unit of Clinical

Pharmacology, Mater Domini University

Hospital, Catanzaro, Italy

Tel +39 09617/2322

Email gallelli@unicz.it

Leiming Zhang

Key Laboratory of Molecular Pharmacology and Drug Evaluation (Yantai University),

Ministry of Education, School of Pharmacy,

Yantai University, Yantai, People's Republic of China

Tel +865356706066

Email zhangleiming2009@I26.com

\begin{abstract}
Saponins are a group of compounds used in clinical practice in the management of several diseases. Escin is a natural mixture of triterpene saponins which mainly consist of several isoforms, in which the $\alpha$ - and $\beta$-escin are predominant. $\beta$-escin is the major active compound that exerts a therapeutic effect by relieving tissue edema, promoting venous drainage, and reducing inflammation. In this review, we describe the features of its glucocorticoid-like activity that could explain its clinical effects. Using PubMed, Embase Cochrane library and reference lists for articles published until October 01, 2020, we documented that escin is likely able to exert its anti-inflammatory and anti-edematous effects through a glucocorticoid-like activity, but without the development of glucocorticoid-like adverse drug reactions.
\end{abstract}

Keywords: escin, mechanism of action, glucocorticoid-like activity, clinical efficacy

\section{Introduction}

Within the bioactive components presented in the plant kingdom, saponins have been extensively applied in clinical practice owing to their broad range of biochemical and pharmacological activities. ${ }^{1}$ Several saponins have been characterized according to the nature of the functional groups present on their aglycone skeleton as well as the number of sugar chains. ${ }^{1}$ As natural compounds composed of a steroidal or triterpenoid aglycone attached with oligosaccharide chains, saponins can be subdivided further into i) steroidal and ii) triterpenoid glycosides, mostly found in monocotyledons and dicotyledons, respectively. ${ }^{2}$ Escin is a natural mixture of triterpene saponins extracted from both seeds and seed shell of Aesculus hippocastanum (dicotyledons) which mainly consist of several isoforms, in which the $\alpha$ - and $\beta$-escin are predominant. ${ }^{3} \beta$-escin is the major active compound that exerts a therapeutic effect by relieving tissue edema, promoting venous drainage, and reducing inflammation. ${ }^{4-6}$ Even if the pharmacological activity of escin has been well reported, ${ }^{5,7}$ in the present review we describe the features of its glucocorticoid-like activity that could explain its clinical effects.

\section{Methods}

PubMed, Embase, Cochrane library and reference lists were searched for articles published until October 01, 2020 using the keywords: "escin", "mechanism action", "cytokines" "edema", "inflammation", "glucocorticoids". Secondary searches included articles cited in sources identified by the previous search. We enclosed randomized control trials (RCTs), open trials, case series, and case reports. 


\section{Glucocorticoids and Glucocorticoid-Like Activity of Escin}

Glucocorticoids are a heterogeneous group of steroidal drugs which are capable to exert anti-inflammatory, antiedematous, and immuno-modulator effects through binding to their receptors. ${ }^{8}$ The glucocorticoid receptor (GR) is a superfamily protein of conserved nuclear receptor and is able to mediate physiologically different actions of the glucocorticoid hormones by acting as a ligand-dependent transcription factor. This class of receptor is a protein shuttling between the cytoplasm and the nucleus, with nuclear translocation occurring upon its binding to glucocorticoid ligand. In fact, unbound GR is localized in the cytoplasm of almost all cells and is stabilized by chaperone proteins such as heat-shock proteins (Hsp) 70, Hsp90, and immunophilin. ${ }^{9}$ Upon binding with glucocorticoids, the GR dissociates from chaperone proteins and translocates together with its ligand into the nucleus within 10 to 30 min. ${ }^{10}$ In the nucleus, homodimers of the glucocorticoid-GR complex interact within 5 to 120 min with specific DNA sequences (glucocorticoid responsive elements), ${ }^{11}$ inducing genomic action with two mechanisms: transrepression and transactivation. ${ }^{10}$

The mechanism of transrepression suppresses the synthesis of proinflammatory proteins such as interleukin (IL)-1, IL-2, IL-6, IL-8, vascular endothelial growth factor, cyclooxygenase-2 (COX-2), prostaglandins (PGs), tumor necrosis factor $-\alpha$ (TNF- $\alpha$ ) and interferon- $\gamma$, involved in inflammation, pain and edema. ${ }^{12,13}$

The mechanism of transactivation results in increases of I $\mathrm{KB}$ (inhibitor of nuclear factor $\kappa \mathrm{B}$ ) and lipocortin 1 , involved in anti-inflammatory and anti-edema effects, and in regulator proteins (involved in metabolism) which are responsible for metabolic-endocrine side effects. ${ }^{13}$

In particular, anti-inflammatory effects are related to the inhibition of NF-kB pathway, ${ }^{14}$ and decrease of both pro-inflammatory genes (such as intercellular adhesion molecule 1 (ICAM-1), TNF- $\alpha$, and IL-1 $\beta$ ) and its transcription factors. ${ }^{15-18}$ The mechanism of action of glucocorticoid also includes the increased expression of proteins with anti-inflammatory activities, such as glucocorticoidinduced leucine zipper (GILZ), ${ }^{19,20}$ which mediates many of the glucocorticoid activities, ${ }^{21,22}$ including inhibition of RAS/RAF/MAPK pathways, ${ }^{23,24}$ and of nuclear factor- $\mathrm{KB}$ (NF-kB) activity. ${ }^{25}$ At the same time, however, through both mechanisms of transrepression and transactivation, glucocorticoids can also induce the development of several adverse drug reactions (eg, immunodepression, infections, bone disease) that limit their clinical use, particularly for a high dose and for a long time. ${ }^{26,27}$ It is worth for us to here mention that the glucocorticoid cortisol (also known as hydrocortisone) is the endogenous ligand for GR and that the polycyclic moiety of the triterpene skeleton in $\beta$ escin displays a similarity with it. Similarities between the pharmacological effects of glucocorticoids and escin have been reported in several publications: oral administration of escin has been shown to inhibit carrageenan-induced paw edema and decrease the production of prostaglandin E2 (PGE2) ${ }^{28}$ in the same model, the systemic administration of dexamethasone or escin were both shown to reduce paw edema, with authors suggesting that the antiinflammatory effect of escin is correlated with the glucocorticoid receptor/NF- $\mathrm{KB}$ signaling pathway, but not the COX/PGF $2 \alpha$ signaling pathway. ${ }^{29}$ On the other hand, corticosterone has been shown to suppress IL- $1 \beta$-induced PGE2 expression. ${ }^{30}$ The possibility that escin and corticosteroid might - at least partially - share similar pharmacologic pathways was also suggested by a publication reporting that escin exerts synergistic anti-inflammatory effects with low doses of glucocorticoids in vivo and in vitro (31).

Therefore, it is possible that both the anti-inflammatory and the anti-edema effects of escin could be related to a modulatory binding with GR, suggesting a glucocorticoid-like activity. Many of the pharmacological and clinical effects reported for escin are focused on the capillary endothelium, and recent literature highlights that the endothelial response to glucocorticoids involves inhibition of pro-inflammatory pathways which determine increased capillary permeability and consequent tissue edema. ${ }^{32}$

It is worth noting that the glucocorticoid-like activity of escin could also be non-genomic. In particular, non-genomic effects of glucocorticoid exist and include direct interaction of GR's ligand with intracellular mediators and modulation of several signaling pathways, eg, protein kinase $\mathrm{C}$, phosphatidylinositol-specific phospholipase $\mathrm{C}$, and src kinase pathways, resulting in rapid glucocorticoid effects. ${ }^{10,33}$ Non genomic glucocorticoid-like effects of escin have been described. In particular, in an animal model of indomethacininduced gastric ulcer, Wang et al documented that intragastric escin (at doses of $0.45,0.9$ or $1.8 \mathrm{mg} / \mathrm{kg}$ ) has a protective effect on gastric mucosa, ${ }^{34}$ through the decrease of the contents of malondialdehyde, TNF- $\alpha$, P-selectin, vascular cell 


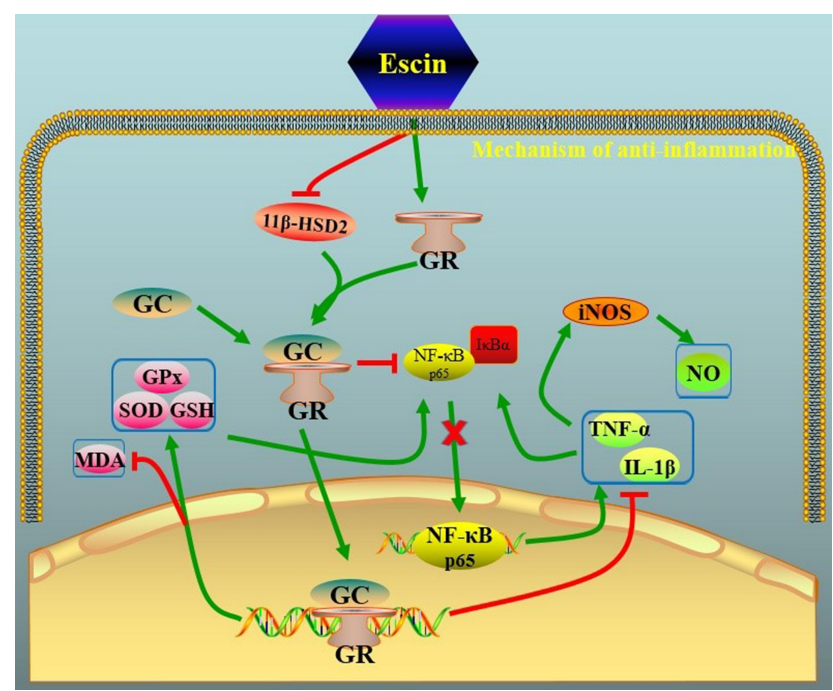

Figure I Schematic representation of glucocorticoid-like mechanism of action of escin. The administration of escin is able to both block II-beta-HSD2 (II- $\beta$ hydroxysteroid dehydrogenase type 2) and induce the expression of GR (glucocorticoid receptor) that binding to GC (glucocorticoid) blocks the activation of NF-KB (nuclear factor kappa-light-chain-enhancer of activated B cells) pathway as well as the transcription of proinflammatory mediators (eg, Interleukin-l beta and tumor necrosis factor (TNF)-alfa) that normally activates lkB (inhibitor of $\mathrm{kB}$ ) pathway and iNOS (inducible nitric oxide synthase). Moreover, the GC-GR complex blocks the activation of MDA (methylenedioxyamphetamine) and induces the transcription of antioxidant mediators (ie, super oxide dismutase, SOD; glutathione, GSH).

adhesion molecule 1 (VCAM-1) and myeloperoxidase activity. These data suggest that the protective effects of escin on gastric mucosa were related to its anti-inflammatory and antioxidant effects, ${ }^{34}$ as it was also documented for other phytochemical compounds. ${ }^{35-38}$ Moreover, recently, Zhao and colleagues evaluated the anti-inflammatory and the antiedematous effects of external use of escin gel (at doses of 0.02 and $0.04 \mathrm{~g} / \mathrm{kg}$ ) in animal models of pain, paw edema and capillary permeability. ${ }^{39}$ In this study, the authors documented that the anti-inflammatory effects of escin were related to down-regulation of pro-inflammatory mediators (ie, PGE2, TNF- $\alpha$, and IL-1 $\beta$ ), through the increased expression of GR. This is in agreement with the study of Xin et al and Jiang et al that reported an increase of the GR's expression in the lungs and livers after escin injection, ${ }^{40,41}$ which leads to a potent protective effect on acute lung and liver injury induced by endotoxin (Figure 1). In particular, as above mentioned, Xin et al evaluated the anti-inflammatory effects of escin (low dose) alone and low dose of escin combined with glucocorticoid (corticosterone low dose; Cort), in both animal model of paw edema, pleuritis and in cell culture of murine macrophagic cells. ${ }^{31}$ In animal model, the administration of escin plus Cort was able to reduce the paw edema, the volume of exudates, and the number of white blood cells in pleuritis. Moreover, in cell culture exposed to lipopolysaccharide revealed that escin plus Cort markedly reduced the content of TNF- $\alpha$ and IL-1 $1 \beta$, suggesting that escin and glucocorticoid have a synergistic anti-inflammatory effect related to the down-regulation of pro-inflammatory mediators. Salvador et al reported that glucocorticoids are able to reduce edema formation by altering endothelial cell barrier function. ${ }^{42}$ The anti-edema effect was also reported for escin. ${ }^{5}$ In particular, Annoni et al reported that escin was able to consistently induce an increase in venous tone upon stimulation of human saphenous vein segments with norepinephrine. ${ }^{43}$ This may explain why escin prevents pathological increases in blood vessel permeability in which reorganization of cytoskeleton is emerging. ${ }^{44,45}$ Moreover, in primary isolated umbilical veins, Bougelet et al showed that escin (100-750 $\mu \mathrm{g} / \mathrm{mL}$ ), was able to reduce the hypoxia-induced endothelial damage as well as the formation of superoxide anions and leukotriene B4. ${ }^{46}$ Therefore, in hypoxic condition causing disruption and reorganization of endothelial cytoskeleton,

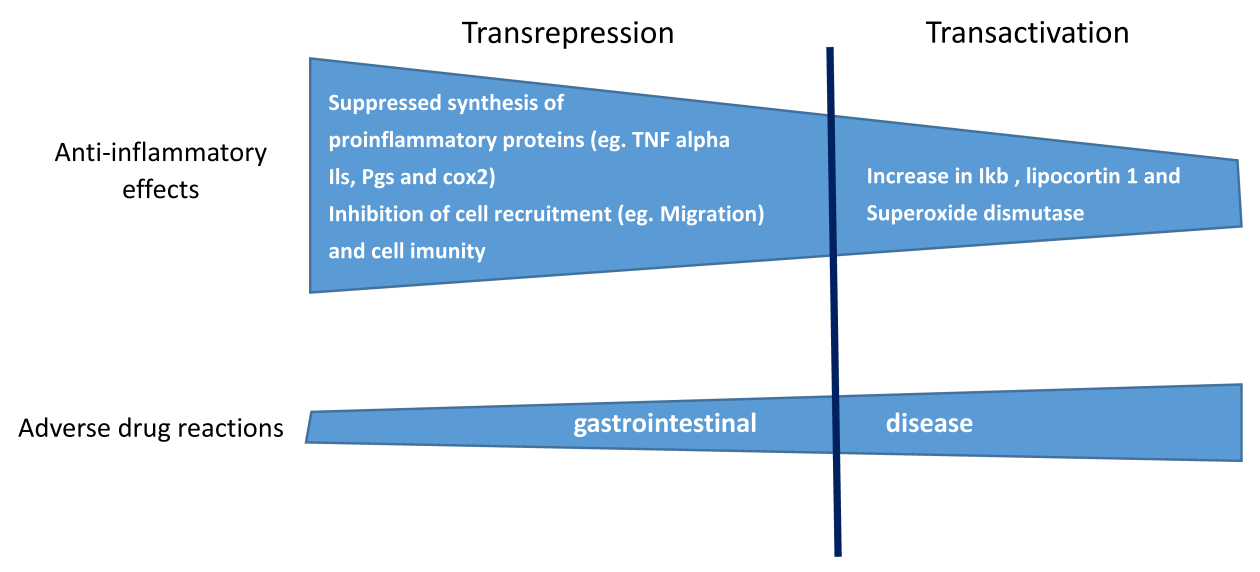

Figure 2 Schematic representation of genomic mechanisms of glucocorticoid-like effects of escin. Escin is able to induce antiinflammatory effects through transrepression and transactivation mechanisms. These mechanisms are also involved in the development of gastrointestinal adverse drug reactions. 
Table I Effects of Escin in Several Experimental Models

\begin{tabular}{|l|l|}
\hline $\begin{array}{l}\text { Experimental } \\
\text { Model }\end{array}$ & Effect of Escin \\
\hline $\begin{array}{l}\text { In vitro pancreatic } \\
\text { lipase }\end{array}$ & $\begin{array}{l}\text { Effectively suppressed the pancreatic lipase } \\
\text { activity }\end{array}$ \\
\hline Male obese mice & Normalized diabetic hyperglycemia \\
\hline $\begin{array}{l}\text { Female obese } \\
\text { mice }\end{array}$ & $\begin{array}{l}\text { Reduced weight gain, adipose tissue mass, lipid } \\
\text { levels in plasma. }\end{array}$ \\
\hline
\end{tabular}

escin may have the capability to limit the vascular damage, thereby limiting vascular extravasation and resulting edema formation.

Taken together, all these studies suggested that both the anti-inflammatory and the anti-edematous effects of escin seem to be related with the involvement of GRs. Even if glucocorticoid use is related to the development of adverse drug reactions, related to genomic mechanisms transactivation and transrepression, ${ }^{10}$ escin use probably for a difference in the effects of transactivation and transrepression (Figure 2) does not induce the development of adverse drug reactions. ${ }^{5,7}$

In agreement with previous experimental studies, other results documented that escin does not increase the endogenous corticosterone secretion, and does not lead to immune cell apoptosis in the spleen and thymus of mice compared with glucocorticoids. ${ }^{47,48}$ Moreover, in an animal model assessing the effect of chronic treatment with escin on postsurgical bone fracture healing and wound healing, Zhang et al have documented that escin does not inhibit bone healing and the wound healing process. ${ }^{49}$ In line with the abovementioned results, Jeepipalli et al reported that escin is able to improve several metabolic outcomes in obese animals (Table 1). ${ }^{50}$ These data suggest that even if escin and glucocorticoids share similar chemical structures (both belonging to tetracyclic triterpenoids), and several pharmacological and clinical effects, they have different safety, with escin expected not to inhibit the physiological tissue repair processes or immunological function.

\section{Conclusion}

Taken together, these data indicate that escin is able to exert the anti-inflammatory and the anti-edematous effects through a glucocorticoid-like activity (ie, partial agonist of GR, increased expression/transcription of GR), but without the development of glucocorticoid-like adverse drug reactions, probably related to its selective agonist with antagonist activity, which attenuate the side effects of glucocorticoid at high level, secreted by body itself or administered.

\section{Ethics Statements}

The authors confirm the table and figures are original.

\section{Acknowledgments}

This research was supported by the National Science Foundation of China (Project No. 81973547). The authors thank Dr. Yuan Du for his support in preparing Figure 1.

\section{Disclosure}

The authors report no conflicts of interest in this work.

\section{References}

1. Biswas T, Dwivedi UN. Plant triterpenoid saponins: biosynthesis, in vitro production, and pharmacological relevance. Protoplasma. 2019;256(6):1463-1486.

2. Lorent JH, Quetin-Leclercq J, Mingeot-Leclercq MP. The amphiphilic nature of saponins and their effects on artificial and biological membranes and potential consequences for red blood and cancer cells. Org Biomol Chem. 2014;12(44):8803-8822. doi:10.1039/ C4OB01652A

3. Costantini A. Escin in pharmaceutical oral dosage forms: quantitative densitometric HPTLC determination. Farmaco. 1999;54(11-12):728-732. doi:10.1016/S0014-827X(99)00090-7

4. Diehm C, Vollbrecht D, Amendt K, Comberg HU. Medical edema protection-clinical benefit in patients with chronic deep vein incompetence. A placebo controlled double blind study. VASA Zeitschrift fur Gefasskrankheiten. 1992;21(2):188-192.

5. Gallelli L. Escin: a review of its anti-edematous, anti-inflammatory, and venotonic properties. Drug Des Devel Ther. 2019;13:3425-3437. doi:10.2147/DDDT.S207720

6. Pittler MH, Ernst E. Horse chestnut seed extract for chronic venous insufficiency. Cochrane Database Syst Rev. 2012;11:CD003230. doi:10.1002/14651858.CD003230.pub4

7. Gallelli L, Zhang L, Wang T, Fu F. Severe acute lung injury related to COVID-19 infection: a review and the possible role for escin. $J$ Clin Pharmacol. 2020;60(7):815-825. doi:10.1002/jcph.1644

8. McEwan IJ, Wright AP, Gustafsson JA. Mechanism of gene expression by the glucocorticoid receptor: role of protein-protein interactions. BioEssays. 1997;19(2):153-160. doi:10.1002/ bies. 950190210

9. Picard D, Khursheed B, Garabedian MJ, Fortin MG, Lindquist S, Yamamoto KR. Reduced levels of hsp90 compromise steroid receptor action in vivo. Nature. 1990;348(6297):166-168. doi:10.1038/ $348166 \mathrm{a} 0$

10. Stahn C, Buttgereit F. Genomic and nongenomic effects of glucocorticoids. Nat Clin Pract Rheumatol. 2008;4(10):525-533. doi: $10.1038 /$ ncprheum0898

11. Almawi WY, Melemedjian OK. Molecular mechanisms of glucocorticoid antiproliferative effects: antagonism of transcription factor activity by glucocorticoid receptor. J Leukoc Biol. 2020;71:9-15.

12. Strehl C, Buttgereit F. Optimized glucocorticoid therapy: teaching old drugs new tricks. Mol Cell Endocrinol. 2013;380(1-2):32-40. doi:10.1016/j.mce.2013.01.026

13. Ishaq M, DeGray G, Mou K, et al. Zap70 signaling pathway mediates glucocorticoid receptor-dependent transcriptional activation: role in the regulation of annexin 1 expression in $\mathrm{T}$ cells. $J$ Immunol. 2007;179(6):3851-3858. doi:10.4049/jimmunol.179.6.3851 
14. Ghosh S, May MJ, Kopp EB. NF-kappa B and Rel proteins: evolutionarily conserved mediators of immune responses. Annu Rev Immunol. 1998;16:225-260. doi:10.1146/annurev.immunol.16.1.225

15. Smale ST. Selective transcription in response to an inflammatory stimulus. Cell. 2010;140(6):833-844. doi:10.1016/j.cell.2010.01.037

16. Stocklin E, Wissler M, Gouilleux F, Groner B. Functional interactions between Stat5 and the glucocorticoid receptor. Nature. 1996;383(6602):726-728. doi:10.1038/383726a0

17. Van Bogaert T, De Bosscher K, Libert C. Crosstalk between TNF and glucocorticoid receptor signaling pathways. Cytokine Growth Factor Rev. 2010;21(4):275-286. doi:10.1016/j.cytogfr.2010.04.003

18. Zhang Z, Jones S, Hagood JS, Fuentes NL, Fuller GM. STAT3 acts as a co-activator of glucocorticoid receptor signaling. J Biol Chem. 1997;272(49):30607-30610. doi:10.1074/jbc.272.49.30607

19. D’Adamio F, Zollo O, Moraca R, et al. A new dexamethasone-induced gene of the leucine zipper family protects $\mathrm{T}$ lymphocytes from $\mathrm{TCR} / \mathrm{CD} 3$-activated cell death. Immunity. 1997;7(6):803-812. doi:10.1016/S1074-7613(00)80398-2

20. Cannarile L, Zollo O, D'Adamio F, et al. Cloning, chromosomal assignment and tissue distribution of human GILZ, a glucocorticoid hormone-induced gene. Cell Death Differ. 2001;8(2):201-203. doi:10.1038/sj.cdd.4400798

21. Hoppstadter J, Kessler SM, Bruscoli S, Huwer H, Riccardi C, Kiemer AK. Glucocorticoid-induced leucine zipper: a critical factor in macrophage endotoxin tolerance. $J$ Immunol. 2015;194 (12):6057-6067. doi:10.4049/jimmunol.1403207

22. Vago JP, Tavares LP, Garcia CC, et al. The role and effects of glucocorticoid-induced leucine zipper in the context of inflammation resolution. $J$ Immunol. 2015;194(10):4940-4950. doi:10.4049/ jimmunol.1401722

23. Ayroldi E, Zollo O, Macchiarulo A, Di Marco B, Marchetti C, Riccardi C. Glucocorticoid-induced leucine zipper inhibits the Raf-extracellular signal-regulated kinase pathway by binding to Raf-1. Mol Cell Biol. 2002;22(22):7929-7941. doi:10.1128/ MCB.22.22.7929-7941.2002

24. Serra R, Grande R, Buffone G, et al. Effects of glucocorticoids and tumor necrosis factor-alpha inhibitors on both clinical and molecular parameters in patients with Takayasu arteritis. J Pharmacol Pharmacother. 2014;5(3):193-196. doi:10.4103/0976-500X.136101

25. Pelaia G, Gallelli L, D’Agostino B, et al. Effects of TGF-beta and glucocorticoids on map kinase phosphorylation, IL-6/IL-11 secretion and cell proliferation in primary cultures of human lung fibroblasts. J Cell Physiol. 2007;210(2):489-497. doi:10.1002/jcp.20884

26. Gallelli L, Ferreri G, Colosimo M, et al. Retrospective analysis of adverse drug reactions to bronchodilators observed in two pulmonary divisions of Catanzaro, Italy. Pharmacol Res. 2003;47(6):493-499. doi:10.1016/S1043-6618(03)00003-3

27. Gonçalves C, Monteiro C, Santos JL. Suspected adverse drug reactions from corticosteroids: analysis of reported notifications to the Portuguese pharmacovigilance system. J Clin Pharmacol. 2020;60 (10):1367-1375. doi:10.1002/jcph. 1630

28. Li M, Lu C, Zhang L, et al. Oral administration of escin inhibits acute inflammation and reduces intestinal mucosal injury in animal models. Evid Based Complement Alternat Med. 2015;2015:503617.

29. Wang H, Zhang L, Jiang N, Wang Z, Chong Y, Fu F. Antiinflammatory effects of escin are correlated with the glucocorticoid receptor/NF- $\mathrm{KB}$ signaling pathway, but not the $\mathrm{COX} / \mathrm{PGF} 2 \alpha$ signaling pathway. Exp Ther Med. 2013;6(2):419-422. doi:10.3892/ etm.2013.1128

30. Wei B, Zhu Z, Xiang M, et al. Corticosterone suppresses IL-1 $\beta$ induced mPGE2 expression through regulation of the $11 \beta$-HSD1 bioactivity of synovial fibroblasts in vitro. Exp Ther Med. 2017;13 (5):2161-2168. doi:10.3892/etm.2017.4238

31. Xin W, Zhang L, Sun F, et al. Escin exerts synergistic anti-inflammatory effects with low doses of glucocorticoids in vivo and in vitro. Phytomedicine. 2011;18(4):272-277. doi:10.1016/j.phymed.2010.08.013
32. Zielinska KA, Van Moortel L, Opdenakker G, De Bosscher K, Van den Steen PE. Endothelial response to glucocorticoids in inflammatory diseases. Front Immunol. 2016;7:592.

33. Strehl C, Spies CM, Buttgereit F. Pharmacodynamics of glucocorticoids. Clin Exp Rheumatol. 2011;29:S13-S18.

34. Wang T, Zhao S, Wang Y, et al. Protective effects of escin against indomethacin-induced gastric ulcer in mice. Toxicol Mech Methods. 2014;24(8):560-566. doi:10.3109/15376516.2014.951815

35. Francomano F, Caruso A, Barbarossa A, et al. $\beta$-caryophyllene: a sesquiterpene with countless biological properties. Appl Sci. 2019;9:5420. doi:10.3390/app9245420

36. Plastina P, Fazio A, Gabriele B. Comparison of fatty acid profile and antioxidant potential of extracts of seven Citrus rootstock seeds. Nat Prod Res. 2012;26(23):2182-2187. doi:10.1080/14786419.2011.647023

37. Cione E, La Torre C, Cannataro R, Caroleo MC, Plastina P, Gallelli L. Quercetin, epigallocatechin gallate, curcumin, and resveratrol: from dietary sources to human microRNA modulation. Molecules. 2019;25(1):63. doi:10.3390/molecules25010063

38. Cione E, Plastina P, Pingitore A, et al. Capsaicin analogues derived from n-3 polyunsaturated fatty acids (PUFAs) reduce inflammatory activity of macrophages and stimulate insulin secretion by beta-cells in vitro. Nutrients. 2019;11(4):915. doi:10.3390/nu11040915

39. Zhao SQ, Xu SQ, Cheng J, et al. Anti-inflammatory effect of external use of escin on cutaneous inflammation: possible involvement of glucocorticoids receptor. Chin J Nat Med. 2018;16(2):105-112. doi:10.1016/S1875-5364(18)30036-0

40. Xin W, Zhang L, Fan H, Jiang N, Wang T, Fu F. Escin attenuates acute lung injury induced by endotoxin in mice. Eur J Pharma Sci. 2011;42(1-2):73-80. doi:10.1016/j.ejps.2010.10.008

41. Jiang N, Xin W, Wang T, et al. Protective effect of aescin from the seeds of Aesculus hippocastanum on liver injury induced by endotoxin in mice. Phytomedicine. 2011;18(14):1276-1284. doi:10.1016/ j.phymed.2011.06.011

42. Salvador E, Shityakov S, Forster C. Glucocorticoids and endothelial cell barrier function. Cell Tissue Res. 2014;355(3):597-605. doi:10.1007/s00441-013-1762-z

43. Annoni F, Mauri A, Marincola F, Resele LF. Venotonic activity of escin on the human saphenous vein. Arzneimittel-Forschung. 1979;29(4):672-675.

44. Bogatcheva NV, Verin AD. The role of cytoskeleton in the regulation of vascular endothelial barrier function. Microvasc Res. 2008;76 (3):202-207. doi:10.1016/j.mvr.2008.06.003

45. Shakhov AS, Verin AD, Alieva IB. [Endothelial cell cytoskeleton reorganization during functional monolayer formation in vitro]. Tsitologiia. 2014;56(1):36-47. Russian.

46. Bougelet C, Roland IH, Ninane N, Arnould T, Remacle J, Michiels C. Effect of aescine on hypoxia-induced neutrophil adherence to umbilical vein endothelium. Eur J Pharmacol. 1998;345(1):89-95. doi:10.1016/S0014-2999(97)01616-6

47. Zhang L, Wang H, Fan H, et al. The potent anti-inflammatory agent escin does not increase corticosterone secretion and immune cell apoptosis in mice. Fitoterapia. 2011;82(6):861-867. doi:10.1016/j.fitote.2011.04.004

48. Wang T, Fu F, Zhang L, Han B, Zhu M, Zhang X. Effects of escin on acute inflammation and the immune system in mice. Pharmacol Rep. 2009;61(4):697-704. doi:10.1016/S1734-1140(09)70122-7

49. Zhang L, Wang $\mathrm{H}$, Wang $\mathrm{T}$, et al. Potent anti-inflammatory agent escin does not affect the healing of tibia fracture and abdominal wound in an animal model. Exp Ther Med. 2012;3(4):735-739. doi: $10.3892 /$ etm. 2012.467

50. Jeepipalli SPK, Du B, Sabitaliyevich UY, Xu B. New insights into potential nutritional effects of dietary saponins in protecting against the development of obesity. Food Chem. 2020;318:126474. doi:10.1016/j.foodchem.2020.126474 


\section{Publish your work in this journal}

Drug Design, Development and Therapy is an international, peerreviewed open-access journal that spans the spectrum of drug design and development through to clinical applications. Clinical outcomes, patient safety, and programs for the development and effective, safe, and sustained use of medicines are a feature of the journal, which has also

been accepted for indexing on PubMed Central. The manuscript management system is completely online and includes a very quick and fair peer-review system, which is all easy to use. Visit http://www. dovepress.com/testimonials.php to read real quotes from published authors.

Submit your manuscript here: https://www.dovepress.com/drug-design-development-and-therapy-journal 